\title{
Improved L-C Resonant Decay Technique for Q Measurement of Quasilinear Power Inductors: \\ New Results for MPP and \\ Ferrite Powdered Cores
}

Janis M. Niedra and Scott S. Gerber

NYMA, Inc.

Brook Park, Ohio

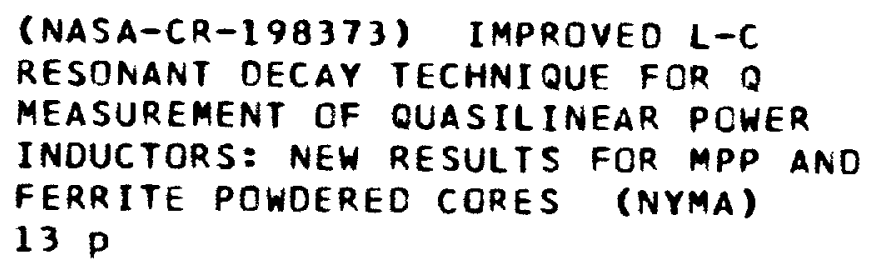

August 1995

Prepared for

Lewis Research Center

Under Contract NAS3-27186

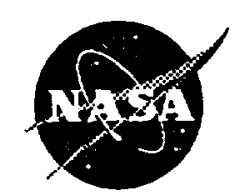

National Aeronautics and Space Administration 
* 


\section{IMPROVED L-C RESONANT DECAY TECHNIQUE FOR Q MEASUREMENT OF QUASILINEAR POWER INDUCTORS: NEW RESULTS FOR MPP AND FERRITE POWDERED CORES}

\author{
Janis M. Niedra \\ NYMA, Inc. \\ NASA Lewis Research Center Group \\ Brook Park, Ohio 44142
}

\author{
Scott S. Gerber \\ NYMA, Inc. \\ NASA Lewis Research Center Group \\ Brook Park, Ohio 44142
}

\section{SUMMARY}

The $\mathrm{L}-\mathrm{C}$ resonant decay technique for measuring circuit $\mathrm{Q}$ or losses is improved by eliminating the switch from the inductor-capacitor loop. A MOSFET switch is used instead to momentarily connect the resonant circuit to an exciting voltage source, which itself is gated off during the decay transient. Very reproducible, low duty cycle data could be taken this way over a dynamic voltage range of at least $10: 1$. Circuit $Q$ is computed from a polynomial fit to the sequence of the decaying voltage maxima. This method was applied to measure the losses at $60 \mathrm{kHz}$ in inductors having loose powder cores of moly permalloy and an $\mathrm{Mn}-\mathrm{Zn}$ power ferrite. After the copper and capacitor losses are separated out, the resulting specific core loss is shown to be roughly as expected for the MPP powder, but anomalously high for the ferrite powder. Possible causes are mentioned.

\section{INTRODUCTION}

Low loss, high frequency power inductors and capacitors are finding increased application in various $\mathrm{L}-\mathrm{C}$ resonant circuits used for efficient conversion of electrical power in space. Knowledge of the losses in separate components is valuable information for the design of improved components, but is often very difficult to obtain because their Qs are typically well over 100; that is, their energy loss is a small fraction of the energy stored. For such components, the power loss equivalent to a sinusoidal voltage-to-current phase shift of less than one degree away from $90^{\circ}$ usually can not be resolved sufficiently well by 8-bit digitizing oscilloscopes suitable for recording at say $100 \mathrm{kHz}$. Also, parasitic phase shifts between the measured voltage and current at high frequencies are known to be a serious source of error in such direct recording and computation methods [1]. Loss measurement in these circumstances thus strains the capabilities of electronic wattmeter methods and one must turn to methods that either measure directly the slow decay with time of a finite L-C stored energy or else use calorimetry to measure the continuous conversion of electrical energy into heat. Highly accurate calorimetry of magnetic component losses has been reported [2], but requires much effort to implement. Energy loss measurement in an L-C tank circuit undergoing damped oscillations is in principle straight forward and has been used for a long time [3,4].
That method, however, gives the total L-C circuit losses, which is short of the final goal if the interest is to study individual components. For the separation of losses one needs relatively low loss reference L or C, accurately characterized for its losses at the frequencies, excitation amplitudes and temperatures of interest. Such references have been based on theoretical calculations of their losses [4] and thus depend on the confidence that one can establish for the prediction models. In any case then, one may be forced to rely on the empiricism of calorimetry to establish the ultimate accuracy of references or to directly characterize components when sinusoidal Fourier analysis is not applicable.

The work described below presents an improved method for establishing decaying oscillations in an L-C resonant circuit that avoids extraneous switch losses. It is suitable for repetitious observation at low duty cycle. Polynomials of degree 10 are shown by experimental example to give a good global fit to the maxima of the damped oscillations in most cases. Using the polynomial coefficients, a simple calculation then yields the exponential damping coefficient, or circuit $Q$, as a smooth function of the excitation amplitude. Results are presented for two quasilinear powder core inductors coupled to a polypropylene film capacitor.

\section{APPARATUS AND PROCEDURES}

The core to be tested was connected directly across a low loss, polypropylene film capacitor, as shown in Figure 1. A power amplifier provided sinusoidal voltage excitation of this core-capacitor tank circuit in a parallel resonant configuration. The excitation frequency could easily be set close to the resonant value $f_{o}$, thereby minimizing the driving current requirements of the amplifier. A high-side solid state switch, driven by a control pulse and utilizing high voltage power MOSFETs, was used to connect the amplifier to the tank circuit just long enough to establish a steady state or desired amplitude. When this switch was opened, the subsequent damped RLC-type oscillations were single-shot recorded by a digitizing oscilloscope, to be computer processed later. The control pulse also gates on the $A C$ source during the ramp-up time only; if left on continuously, the AC source would couple through the MOSFET capacitances to produce an unacceptable beat distortion of the decaying oscillations when these 
oscillations were below a quarter or so of their initial peak. Repetitious electronic switching then lets one observe variations as the source amplitude and frequency are adjusted. Since there is no switch in the core-capacitor loop itself, the only significant energy dissipation is confined to the core and capacitor and their short interconnections. The effects of the open-state MOSFET switch could easily be verified to be negligible by substituting a mechanical switch; for excitations above a few volts, we found the type MTM2N85 MOSFETs, rated $2 \mathrm{~A}$ and $850 \mathrm{~V}$, to be acceptable. And at the frequencies not exceeding $100 \mathrm{kHz}$ of interest here, radiative losses from this quite compact core-capacitor loop may be expected to be negligible compared to the component losses. Thus extraneous losses are minimized by this setup, which also permits easy, repetitive operation at low duty cycle so as to minimize component heating. Voltage source interference through the MOSFET capacitances is also eliminated, since the signal source is gated off during the decay transient. To avoid large amplifier current spikes upon switch tumon, we used either a simple series snubbing circuit (not shown), occasionally a programmed ramp-up of the source generator, or else relied on inductances in the power source itself. To clip positive or negative destructive voltage spikes upon switch opening, we used two circuits shunting the source, each consisting basically of a diode in series with a capacitor. The capacitor charges to the steady state peak voltage value and clips any voltage spike above that value; charge bleedoff and current limiting resistors are necessary.

\section{DISCUSSION OF RESULTS FOR SAMPLE CORES}

A high frequency toroidal inductor having a cross-section $A_{c}=1.1 \mathrm{~cm}^{2}$ and a mean path length $l_{c} \approx 17.9 \mathrm{~cm}$ was made by fulling a plastic core case with loose moly permalloy powder (MPP) of a type used in the manufacture of $\mu_{\mathrm{T}}=200 \mathrm{MPP}$ cores. The filled case was then wound with 53 turns of 13-gauge equivalent, $20 \mathrm{kHz}$ rated Litz wire. At $0.45 \mathrm{~V}$ peak, $20 \mathrm{kHz}$ excitation, an impedance bridge indicated an inductance of $29.3 \mu \mathrm{H}$ and an equivalent series resistance (ESR) of $0.0368 \Omega$, giving a $Q$ of 100 . Another such inductor was prepared by substituting powdered (particle size $\leq 100$ microns) Ceramic Magnetics, Inc. type MN80 Mn-Zn power ferrite for the MPP. Bridge measurements, as above, gave an inductance of $35.6 \mu \mathrm{H}$ and an ESR of $0.0375 \Omega$, and hence a $Q$ of 119 , for this core. At a test frequency of $66.7 \mathrm{kHz}$, bridge measurements gave substantially unchanged inductances, and Qs of $144(E S R=0.085 \Omega)$ and $299(E S R=0.050 \Omega)$ for these powdered MPP and ferrite inductors, respectively; note that $Q=|X| / R$ for an inductor or a capacitor, where $X$ is the reactance and $R$ is the ESR.

These inductors were then resonated with polypropylene film capacitors of various values in the setup described above. Figures $2 \mathrm{a}$ and $2 \mathrm{~b}$ present samples of the basic resonant decay curves obtained for the two inductors when coupled to a low loss, $0.22 \mu \mathrm{F}$, polypropylene film capacitor having a bridge determined ESR of $0.030 \Omega$ $(Q=357)$ at $66.7 \mathrm{kHz}$. Similar data, not shown, were taken over several lower, contiguous voltage ranges and combined in order to improve resolution over a wide voltage range. Further, low excitation level, bridge measurements of the $Q$ of this capacitor in the frequency (f) range 20 to $100 \mathrm{kHz}$ are well approximated by

$$
\mathrm{Q}_{c}=9.29 \times 10^{7} \mathrm{f}^{-1.12},
$$

which is assumed, for lack of better data, to hold at higher voltages as well when calculating $Q_{1}$ for the inductor.

In a strictly linear L-C-R circuit, the decay of voltage oscillations proceeds according to the form

where

$$
v(t)=v_{0} e^{-\alpha t} \sin (\omega t),
$$

and

$$
\alpha=R /(2 L)
$$

$$
\omega=\left[(1 / L C)-\alpha^{2}\right]^{1 / 2} \text {. }
$$

If $R$ is written as a sum of the component ESRs $R_{I}$ and $R_{c}$, then the decay constant $\alpha$ can be written in terms of the component $Q s$ as

$$
\alpha=(\omega / 2)\left[Q_{L}^{-1}+\left(\omega^{2} L C Q\right)^{-1}\right] .
$$

However, for low loss components, $\alpha$ is small and $\omega^{2} L C \approx 1$ quite accurately, making

$$
\alpha \approx(\omega / 2)\left(Q_{L}^{-1}+Q_{C}^{-1}\right)
$$

a good approximation and $Q=\omega /(2 \alpha)$ a convenient definition of the L-C-R system $Q$. To get exact results, LC can be eliminated from Equation (5) by using the definition of $\omega$, obtaining

$$
2 \alpha / \omega=Q_{L}^{-1}+Q_{c}^{-1}+(\alpha / \omega)^{2} Q_{c}^{-1},
$$

or

$\alpha / \omega=\left(Q_{L}^{-1}+Q_{c}^{-1}\right)\left[1+\left(1-Q_{c}^{-1} Q_{L}^{-1}-Q_{c}^{-2}\right)^{1 / 2}\right]^{-1}$

Both $\alpha$ and $\omega$, and hence the system $Q$, can be derived from the experimental data in Figure 2. Generally these quantities will vary somewhat with the time during decay because the circuit elements - especially the inductor - are not entirely linear with the excitation amplitude. Thus the frequency was found by a simple zero crossing analysis of the data and $\alpha$ was derived from a plot of the decaying peak voltage as described below.

The peak magnitudes of the oscillations given by Equation (2) are

$$
|v|_{\max , n}=v_{0}\left[1+(\alpha / \omega)^{2}\right]^{-1 / 2} e^{-\alpha t_{0}},
$$

which occur at times

$\mathrm{t}_{\mathrm{n}}=(\mathrm{n}-1) \pi \omega^{-1}+\omega^{-1} \sin ^{-1}\left[1+(\alpha / \omega)^{2}\right]^{-1 / 2}, \mathrm{n}=1,2,3 \ldots$ 
Let $p$ be a polynomial, or some other function, fitted to the experimentally determined sequence of decaying voltage peaks. Figure 3 shows two examples of 10th degree polynomials least-squares fitted to the positive peaks in Figure 2. The exponential form in Equation (9) can be made to fit the decaying voltage peaks (now represented by p) quite well locally, although not in general globally, by adjusting the value of $\alpha$, etc.. Replacing $t_{n}$ by a continuous $t$, one can write

$$
p(t)=v_{0}\left[1+(\alpha / \omega)^{2}\right]^{-1 / 2} e^{-\alpha t},
$$

where $\alpha$ is at most a slowly varying function of $t$. This implies that

$$
\alpha(t) \approx-p^{\prime}(t) / p(t)
$$

and so the system $Q$ can be computed from

$$
Q(t) \approx-(\omega / 2) p(t) / p^{\prime}(t)
$$

Using the above methods, we computed the system $Q$ over a wide voltage range of both the MPP and MN80 ferrite loose powder inductors when resonated with the capacitor characterized by Equation (1). Results are presented in Figure 4, which shows the splicing of data from several voltage ranges. Instrumentation errors, such as amplifier nonlinearities and offsets, as well as polynomial fit errors, contribute to the plot mismatches and unevenness seen. Even though the high degree polynomial fits appear to be very good in Figure 3, the derivatives of these polynomials tend to oscillate increasingly at the lower voltages of a range, causing $Q$ calculation errors in Equation (13). Also, frequency determination becomes inaccurate as the voltage approaches the instrumentation noise level. These errors are thought to be major contributors to the $Q$ oscillations evident near the lower ends of the voltage ranges. The significant shifting in frequency with voltage level, especially in the case of the MN80, appears to be a real material effect due to the competing effects of variations in $\mathrm{L}$ and the losses. Thus one expects the frequency to increase at high voltages due to onset of magnetic saturation.

It is apparent from Figure 4 that the two powdered cores have remarkably different loss characteristics with variations in voltage. Whereas the system $Q$ using MPP powdered material slopes down gradually with increasing voltage, the $Q$ using MN80 powder drops far more rapidly, starting significantly above the $Q$ for MPP when below a volt and falling far below the $Q$ for MPP at 100 volts. This may be contrary to expectation, based on the fact that for a sinusoidal magnetic induction (B) of $1 \mathrm{kG}$, the solid MN80 has lower volume specific losses than does a solid $\mu_{\mathrm{T}}=26 \mathrm{MPP}$ core or 1 -mil Supermalloy tape [5]. See Table I for the core loss ranking of MN80 relative to some other well known high frequency magnetic materials. One might speculate mechanical agitation loss differences due to $B$-field or magnetostrictive forces on the particles or loss differences due to surface effects, but presently the cause is unknown.

Table I. Core Loss of Sample Commercial Materials at $25 \mathrm{C}$ and $\mathrm{B}=0.1 \mathrm{~T}$ at Selected Available Frequencies

\begin{tabular}{|l|c|c|c|}
\hline & $\underline{50 \mathrm{kHz}}$ & $\underline{60 \mathrm{kHz}}$ & $\underline{100 \mathrm{kHz}}$ \\
\hline$" 200 \mu " \mathrm{MPP}$ & $0.63 \mathrm{~W} / \mathrm{cm}^{3}$ & $0.84 \mathrm{~W} / \mathrm{cm}^{3}$ & $1.88 \mathrm{~W} / \mathrm{cm}^{3}$ \\
\hline$" 26 \mu " \mathrm{MPP}$ & 0.22 & 0.28 & 0.56 \\
\hline $\begin{array}{l}\text { Supermalloy } \\
\text { (1-mil tape) }\end{array}$ & 0.091 & & 0.28 \\
\hline MN80 & & & 0.15 \\
\hline MN8CX & & & 0.024 \\
\hline
\end{tabular}

The peak B-field is of basic interest for the magnetic core and was calculated from

$B_{p k}=27 V_{p k} / f,\left(B_{p k}:\right.$ tesla, f: Hz, $V_{p k}:$ volts).

This formula incorporates the core geometry and a rough correction for the core-to-winding air space and treats the powder as a uniform medium. Assuming that Equation (1) for $Q_{c}$ is valid up to the voltages of interest here, the inductor $Q_{L}$ can be found from Equation (6). Resulting plots of $Q_{L}$ versus $B_{p k}$ are shown in Figure 5. The range of $B_{p k}$ covered is seen to be from around a few gauss to 2 kilogauss. The disparity in $\mathrm{Q}_{\mathrm{L}}$ between the two inductors remains and can only be ascribed to a difference in losses in the powdered materials.

The separation of losses can be carried out one step further, to arrive at the volume-specific core loss (W), in watts $/ \mathrm{m}^{3}$. From basic considerations of the losses per cycle, one can derive the total ESR of an inductor with a magnetic core to be

$$
\mathrm{R}_{\mathrm{s}}=2 \mu \mathrm{L}_{\mathrm{c}} \mathrm{WB}_{\mathrm{pk}}^{-2}+\mathrm{R}_{\mathrm{w}},
$$

where $R_{w}$ is the resistance of the winding and $L_{c}$ is the inductance of the core volume alone with magnetic material present. Assuming no proximity effects on $\mathbf{R}_{\mathbf{w}}$ due to the core, the $R_{w}$ is the same as the resistance of the inductor with no core and hence can be measured as a function of $f$. Thus in Q-terminology, the $Q_{0}$ of this no-core inductor was found from bridge measurements to be well approximated by

$$
\begin{aligned}
Q_{0}= & f \cdot\left(9.94 \times 10^{-4}-6.095 \times 10^{-9} \mathrm{f}+1.103 \times 10^{-13} \mathrm{f}^{2}-\right. \\
& \left.8.671 \times 10^{-19} \mathrm{f}^{3}\right),
\end{aligned}
$$


for $f$ in the range $10 \mathrm{kHz}$ to $100 \mathrm{kHz}$, where the inductance $\left(\mathrm{L}_{0}\right)$ was nearly constant at $4.67 \times 10^{-6} \mathrm{H}$. Both $\mathrm{L}_{\mathrm{o}}$ and $\mathrm{L}$ always include an inductance $\left(\mathrm{L}_{\mathrm{p}}\right)$ of the core-towinding peripheral air space, which gives rise to some correction factors in the formulas below; e.g., $\mathrm{L}=\mathrm{L}_{\mathrm{c}}+\mathrm{L}_{\mathrm{f}}=$ $\mu_{i}\left(L_{o}-L_{p}\right)+L_{p}$. For the present inductors, $L_{p}=2.66 \times 10^{-6} H_{\text {. }}$

Equation (15) implies that the $Q$ of the core material itself is

$$
\mathrm{Q}_{\text {core }}=\frac{\omega \mathrm{B}_{\mathrm{pk}}^{2}}{2 \mu \mathrm{W}}
$$

and satisfies

$$
\frac{1}{Q_{L}}=\frac{1}{a_{1} Q_{\text {core }}}+\frac{1}{a_{2} \mu_{1} Q_{0}},
$$

where

$$
a_{1}=1+\left[\mu_{r}\left(\frac{L_{0}}{L_{p}}-1\right)\right]^{-1}
$$

and

$$
a_{2} \equiv 1-\frac{L_{p}}{L_{0}}\left(1-\frac{1}{\mu_{z}}\right)
$$

are factors correcting for the existence of $L_{p}$. Likewise, $L_{p}$ affects the value of $\mu_{\mathrm{T}}$, as computed from

$$
\mu_{\mathrm{r}}=\left[C^{-1}\left(\alpha^{2}+\omega^{2}\right)^{-1}-L_{\mathrm{p}}\right] /\left(\mathrm{L}_{0}-\mathrm{L}_{\mathrm{P}}\right) ;
$$

this formula follows from Equation (4). The specific core loss was then computed from

$$
\mathrm{W}=\frac{\mathrm{a}_{1} \omega \mathrm{B}_{\mathrm{pk}}^{2}}{2 \mu_{0} \mu_{\mathrm{r}}}\left(\frac{1}{\mathrm{Q}_{\mathrm{I}}}-\frac{1}{\mathrm{a}_{2} \mu_{\mathrm{T}} \mathrm{Q}_{0}}\right),
$$

which is a combination of Equations (17) and (18), giving the plots shown in Figure 6. The MPP plot is well fit by

$$
W=90.19 B^{2095},\left(w / \mathrm{cm}^{3}\right)
$$

which for $f=62 \mathrm{kHz}$ and $B<0.1 \mathrm{~T}$ is somewhat above

$$
W=2.92 \times 10^{-6} \mathrm{f}^{1.58} \mathrm{~B}^{2.29},\left(\mathrm{w} / \mathrm{cm}^{3}\right)
$$

obtained from manufacturer's data [6] for solid, $\mu_{4}=200$, MPP material by scaling to the powder density of 5.39 $\mathrm{g} / \mathrm{cm}^{3}$. For the MN80 powder [7] $\left(2.62 \mathrm{~g} / \mathrm{cm}^{3}\right)$, one would have expected the losses not to exceed about $0.06 \mathrm{w} / \mathrm{cm}^{3}$ at 50 to $60 \mathrm{kHz}$ and $0.1 \mathrm{~T}$, instead of the $3 \mathrm{w} / \mathrm{cm}^{3}$ observed.

\section{SUMMARY AND CONCLUSIONS}

Energy dissipation or $Q$ measurements were performed on an inductor-capacitor resonant circuit by capturing its decaying oscillations as a single-shot transient on a digitizing oscilloscope. Switching losses and disturbances were eliminated by coupling the inductor directly to the capacitor in a compact loop. This circuit was then excited by a signal burst near the resonant frequency, momentarily applied from an amplifier through a MOSFET switch. The $850 \mathrm{~V}, 2$ A power MOSFETS introduced negligible additional capacitance and served well at excitation levels above 2 volts. Switching, oscilloscope triggering and the signal source could all be easily controlled by a single gating pulse to give reproducible data at a low duty cycle. This eliminates voltage source interference through the MOSFET capacitances, since the source is gated off during the decay. The noise limited, maximum useful dynamic voltage range usually spanned a ratio of at least $10: 1$. System $Q$ was computed from a polynomial fit to the sequence of the decaying voltage maxima.

This resonant decay technique was then applied to measure the losses in two inductors having magnetic cores consisting of moly permalloy (MPP) and $\mathrm{Mn}-\mathrm{Zn}$ power ferrite loose powdered materials. An independently characterized, low loss polypropylene film capacitor was used to establish resonance at about $60 \mathrm{kHz}$. From manufacturers' data for these core materials in their bulk solid form, one expects the powdered power ferrite to have $60 \mathrm{kHz}$ losses significantly below the losses of the MPP powder, making the powdered ferrite a candidate material for low loss power inductors. The $Q$ measurements taken unfortunately indicated the contrary for these as is powders. After the capacitor and copper losses are separated out, the resulting specific core loss plots show that the ferrite powder has significantly higher $60 \mathrm{kHz}$ losses than does the MPP powder for peak magnetic inductions above about $2.5 \mathrm{mT}$, which is the loss curve crossover point. The MPP powder losses at least at $0.1 \mathrm{~T}$ are about as expected from manufacturers data scaled to the density of the powder, but this loss anomaly is significantly increased in the ferrite powder. Particle surface effects, stresses induced by crushing the ferrite to a powder, or losses due to mechanical agitation of the powder in the core may be responsible. More work is needed to define and control the causes.

\section{ACKNOWLEDGMENTS}

The authors gratefully acknowledge Eric $D$. Baumann and Eric Overton for assistance and use of their automated impedance bridge. This work was sponsored by the NASA Lewis Research Center under contract NAS3-27186.

\section{REFERENCES}

1. F. Dong Tan et al., "A Practical Approach for Magnetic Core-Loss Characterization," IEEE APEC Proceedings, San Diego, CA, March 1993, pp. 572-578.

2. D.K. Conroy et al., "Measurement Techniques for the Design of High-Frequency SMPS Transformers," IEEE APEC Proceedings, New Orleans, LA, February 
1988, pp. 341-351.

3. E.B. Moullin, "A Method of Measuring the Effective Resistance of a Condenser at Radio Frequencies, and of Measuring the Resistance of Long Straight Wires," Proc. Royal Soc. A 137, 1932, pp. 116-133.

4. J.A. Ferreira and J.D. van Wyk, "Experimental Evaluation of Losses in Magnetic Components for Power Converters," IEEE Transactions on Industry Applications 27, no. 2, March April 1991, pp. 335-338.

5. W.R. Wieserman et al., "High Frequency, High Temperature Specific Core Loss and Dynamic B-H Hysteresis Loop Characteristics of Soft Magnetic Alloys," 25th IECEC Proceedings, Reno, NE, August 1990. Also NASA TM-103164.

6. "MPP and High Flux Cores for Filter and Inductor Applications," Magnetics Division of Spang \& Company, Butler, PA, 1991, p. 24.

7. "Engineered Ferrites," Ceramic Magnetics, Inc., Fairfield, New Jersey, 1988, pp. 14-15. 


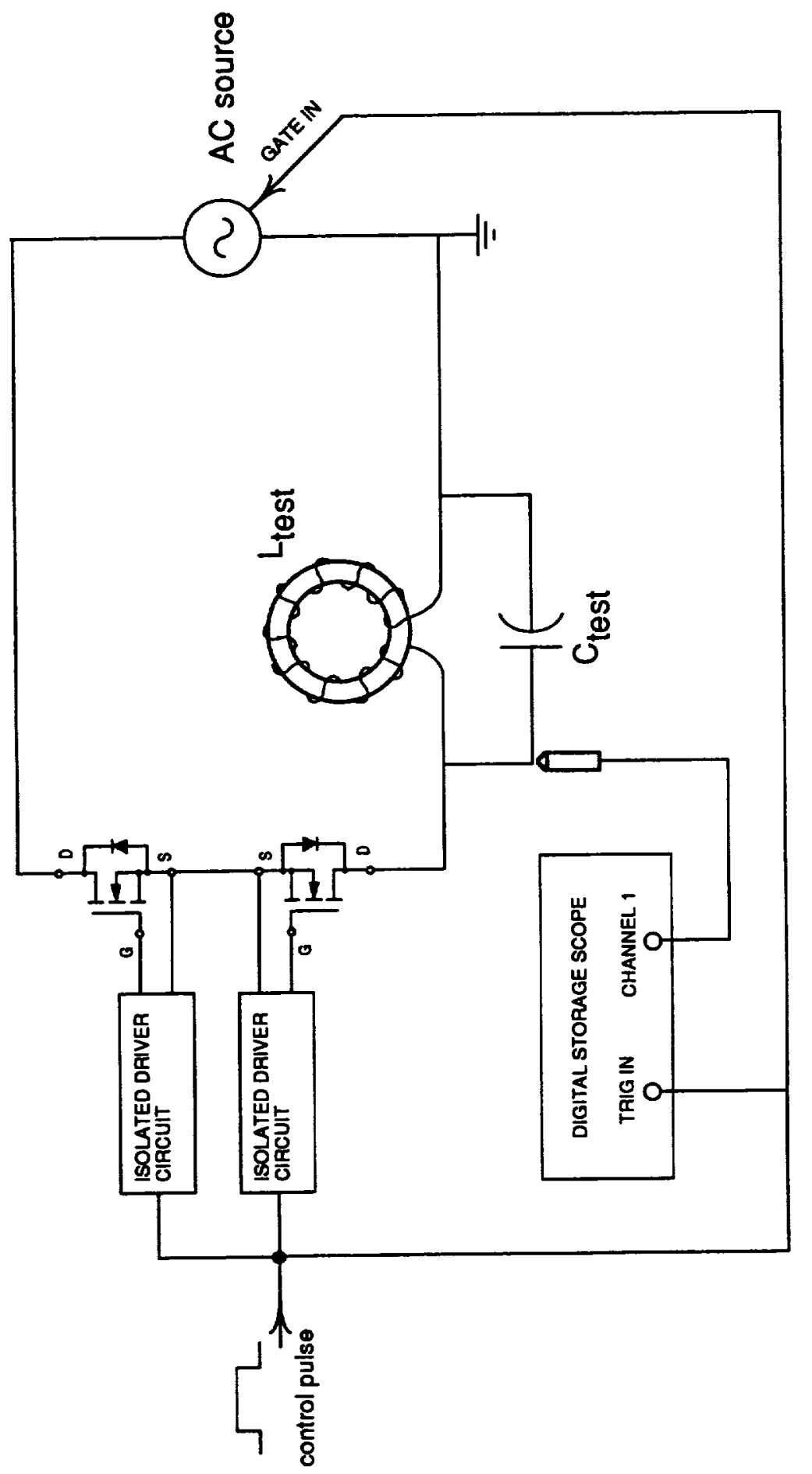

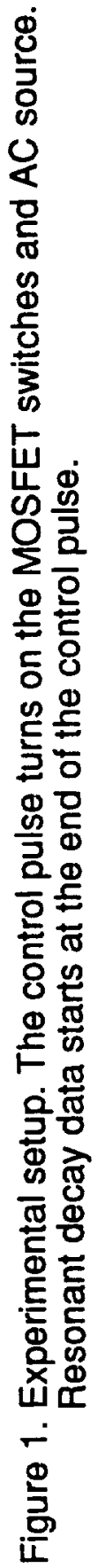




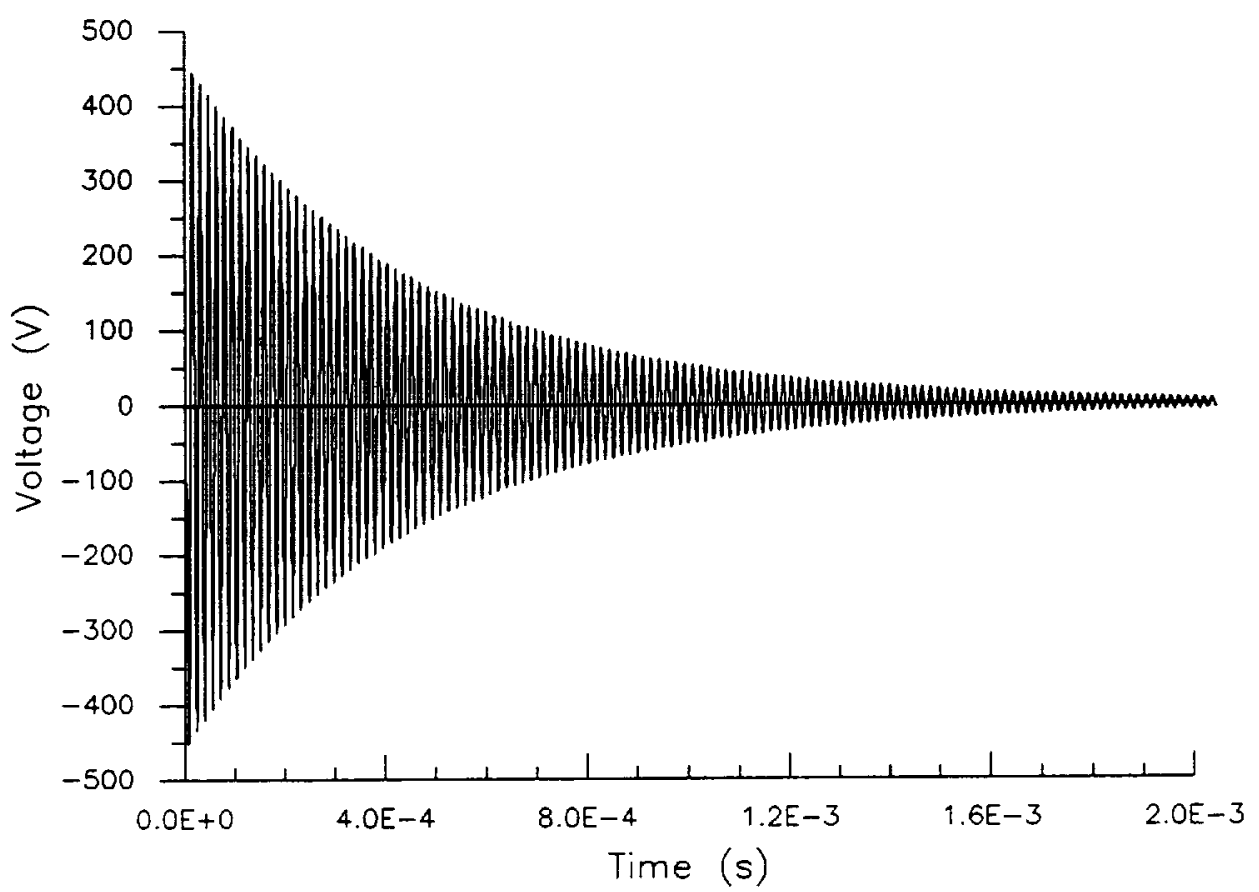

a. Powdered MPP inductor.

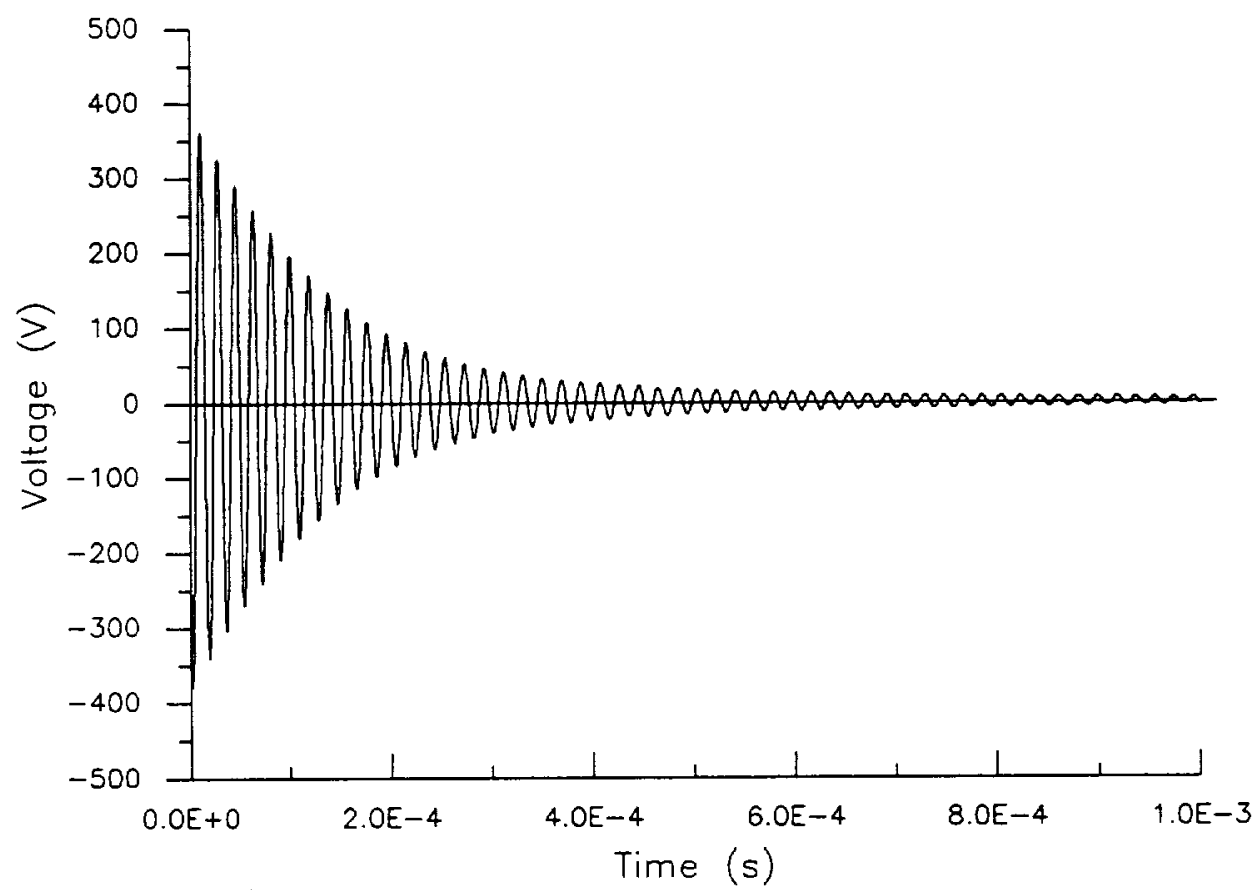

b. Powdered MN80 ferrite inductor.

Figure 2. L-C-R system high valtage decay waveforms captured on a digital storage oscilloscope. 


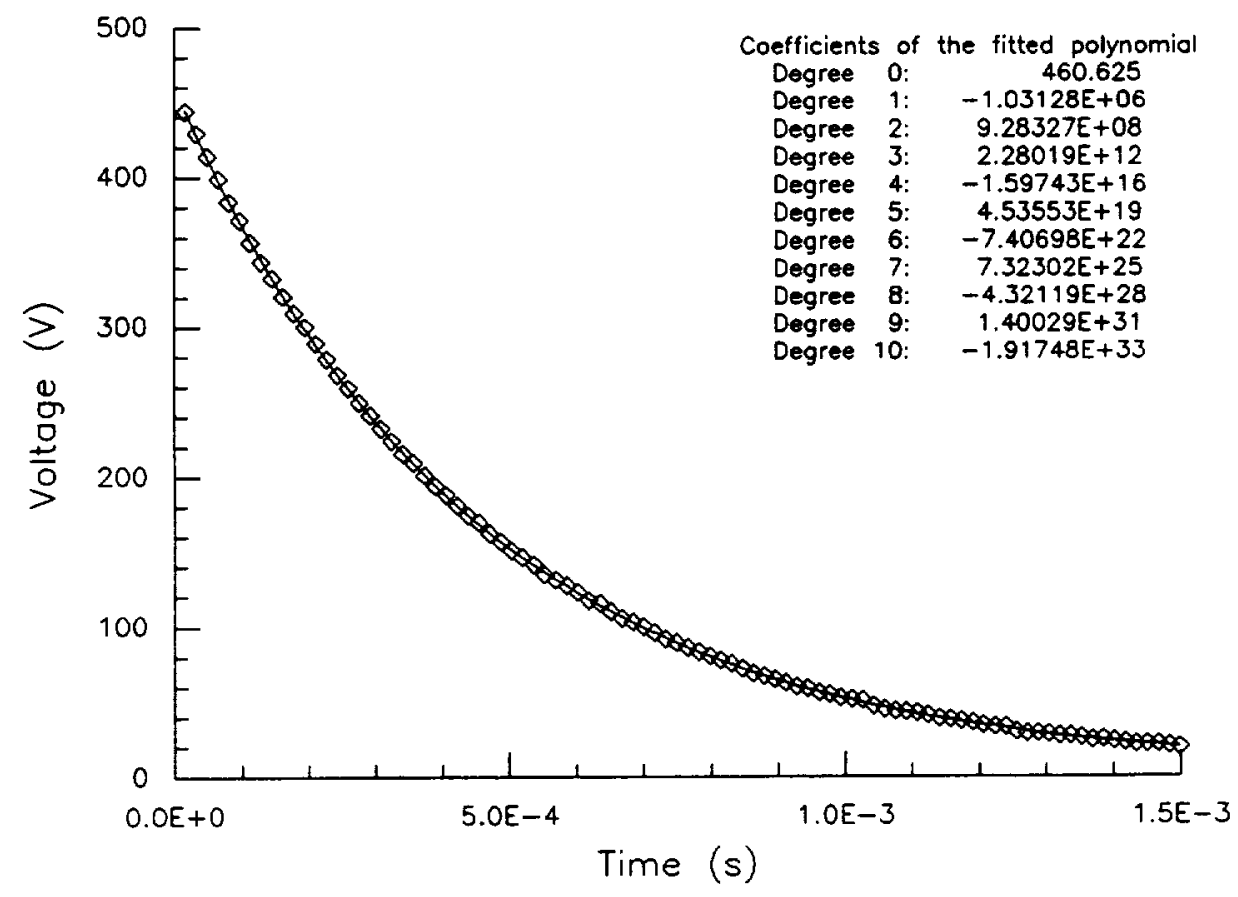

a. Powdered MPP inductor.

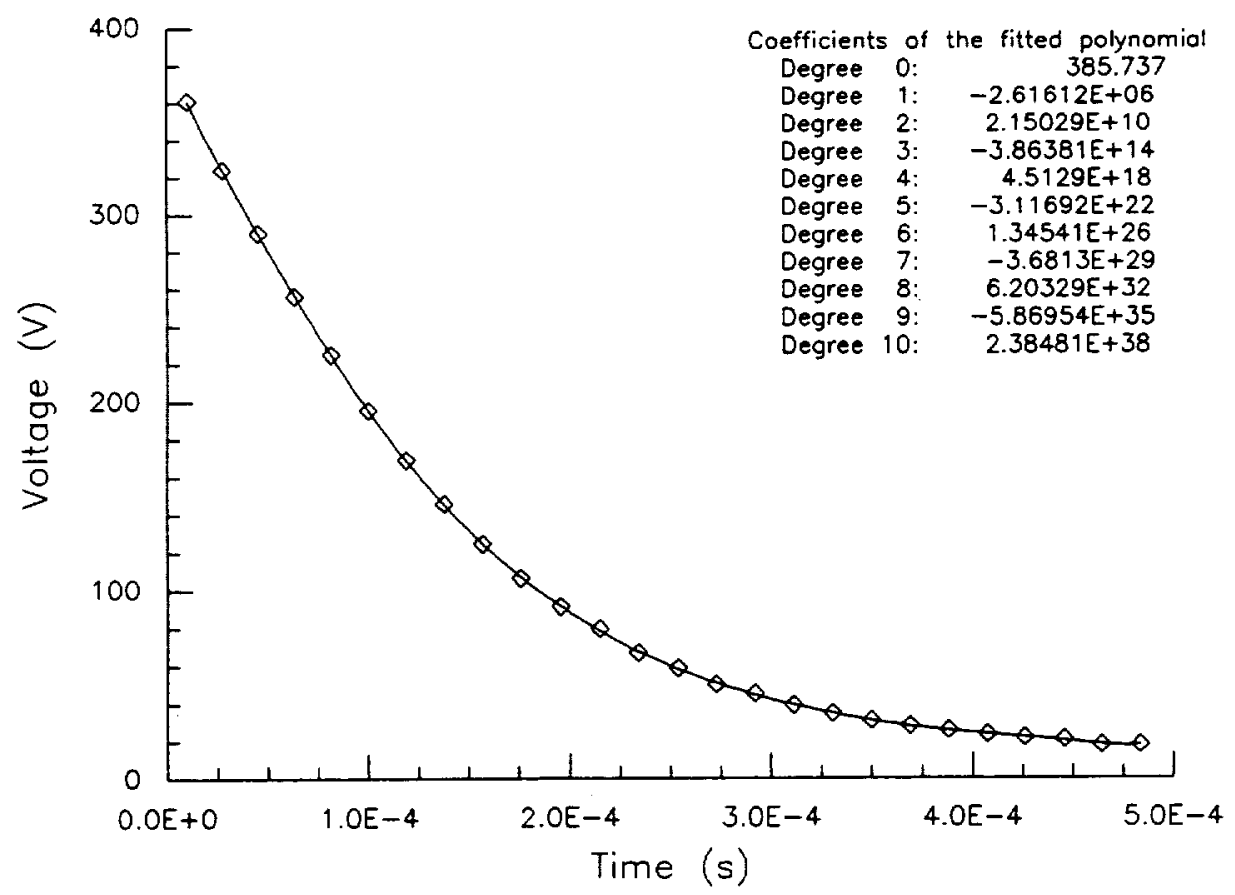

b. Powdered MN80 ferrite inductor.

Figure 3. Polynomials of degree 10 fitted to the locus of decaying positive voltage peoks of the waveforms shown in Figure 2. 


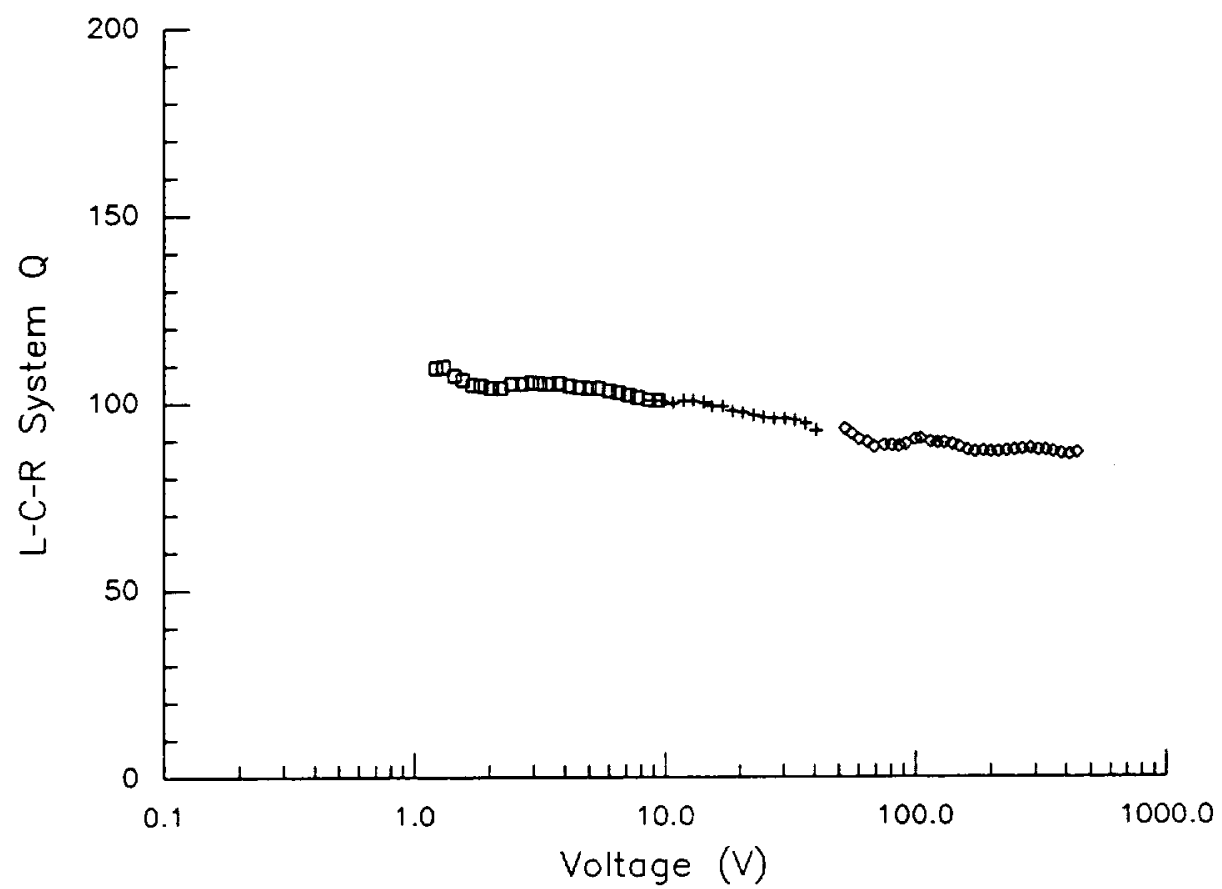

a. Powdered MPP inductor. Frequency variation is 60 to $62 \mathrm{kHz}$, from low to high voltage.

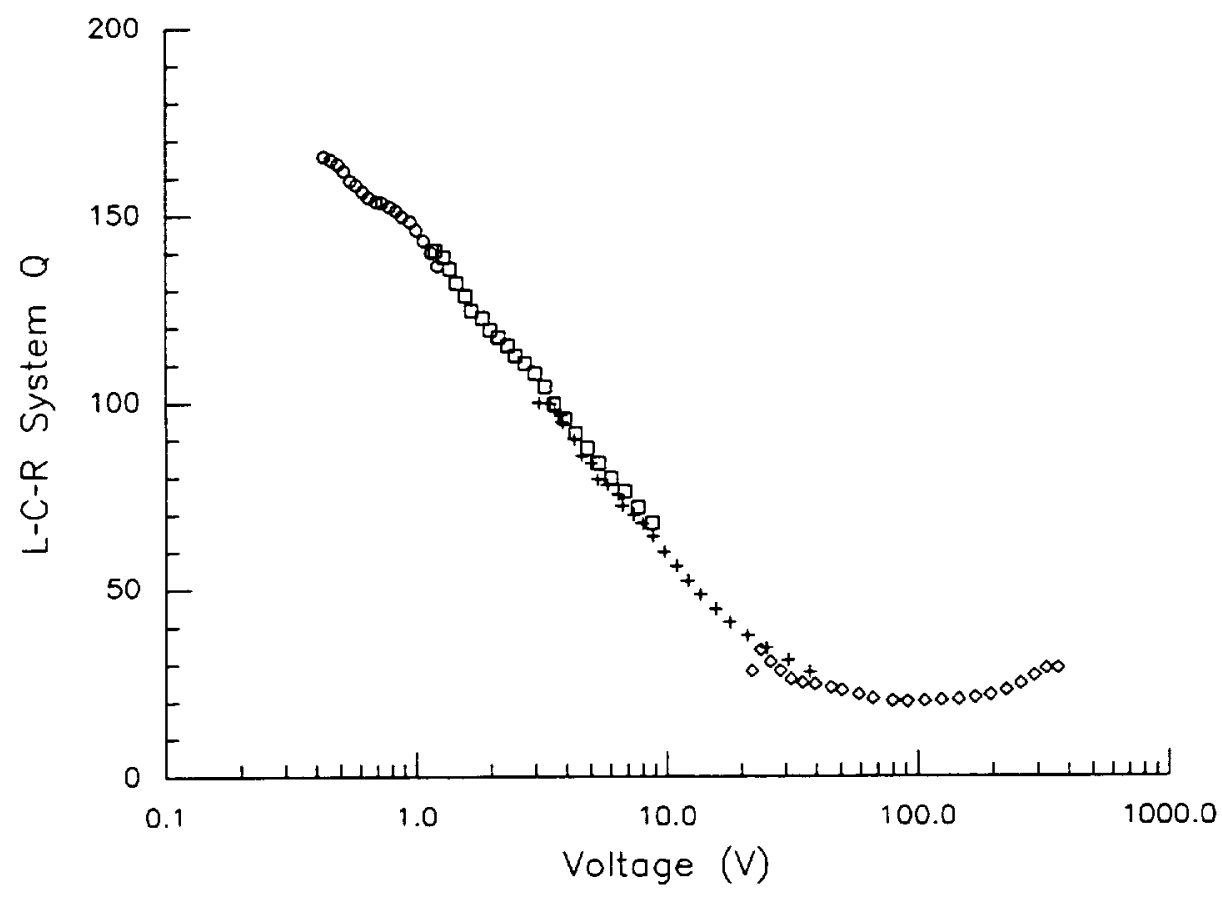

b. Powdered MN80 ferrite inductor. Frequency decreases from $53.5 \mathrm{kHz}$ at low voltage to $51 \mathrm{kHz}$ at 50 volts and rises to $58 \mathrm{kHz}$ at maximum voltoge.

Figure 4. L-C-R system $Q$ as a function of voltage. Data was combined from several voltage ranges to improve resolution. Points represent locations of computation only, using Eq. 13. 


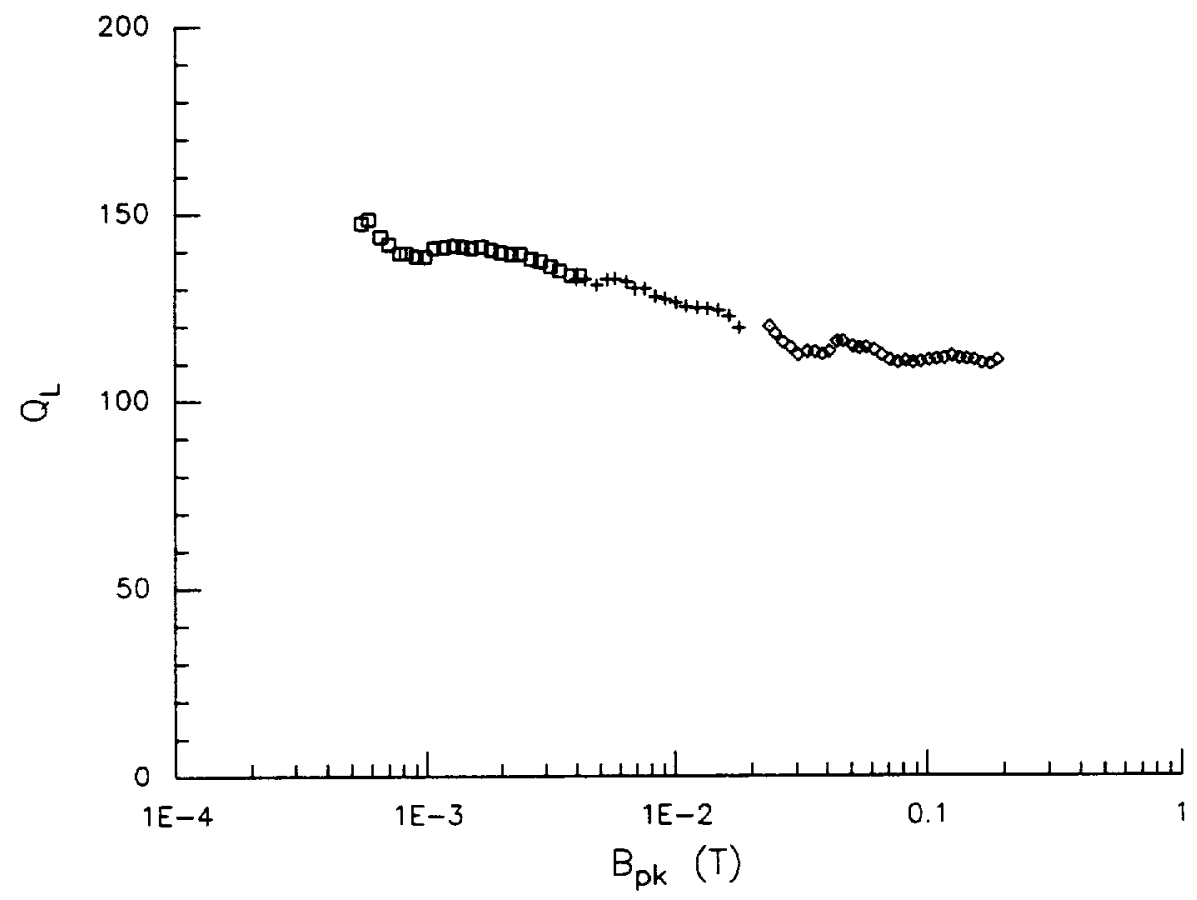

a. Powdered MPP inductor.

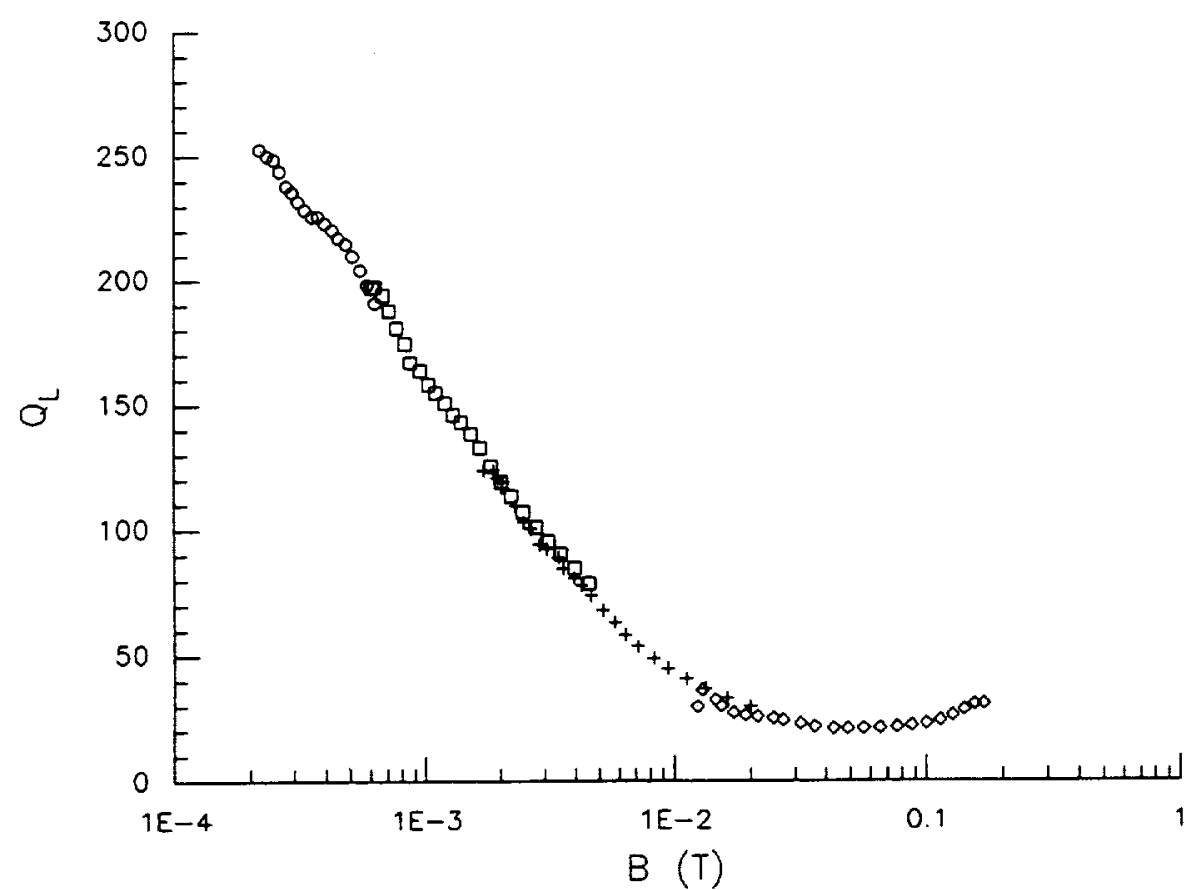

b. Powdered MN80 ferrite inductor.

Figure 5. $Q_{L}$ of the inductor, derived from the plots of Figure 4 and Equations 1 and 4 versus peak $B$-field in the core. 


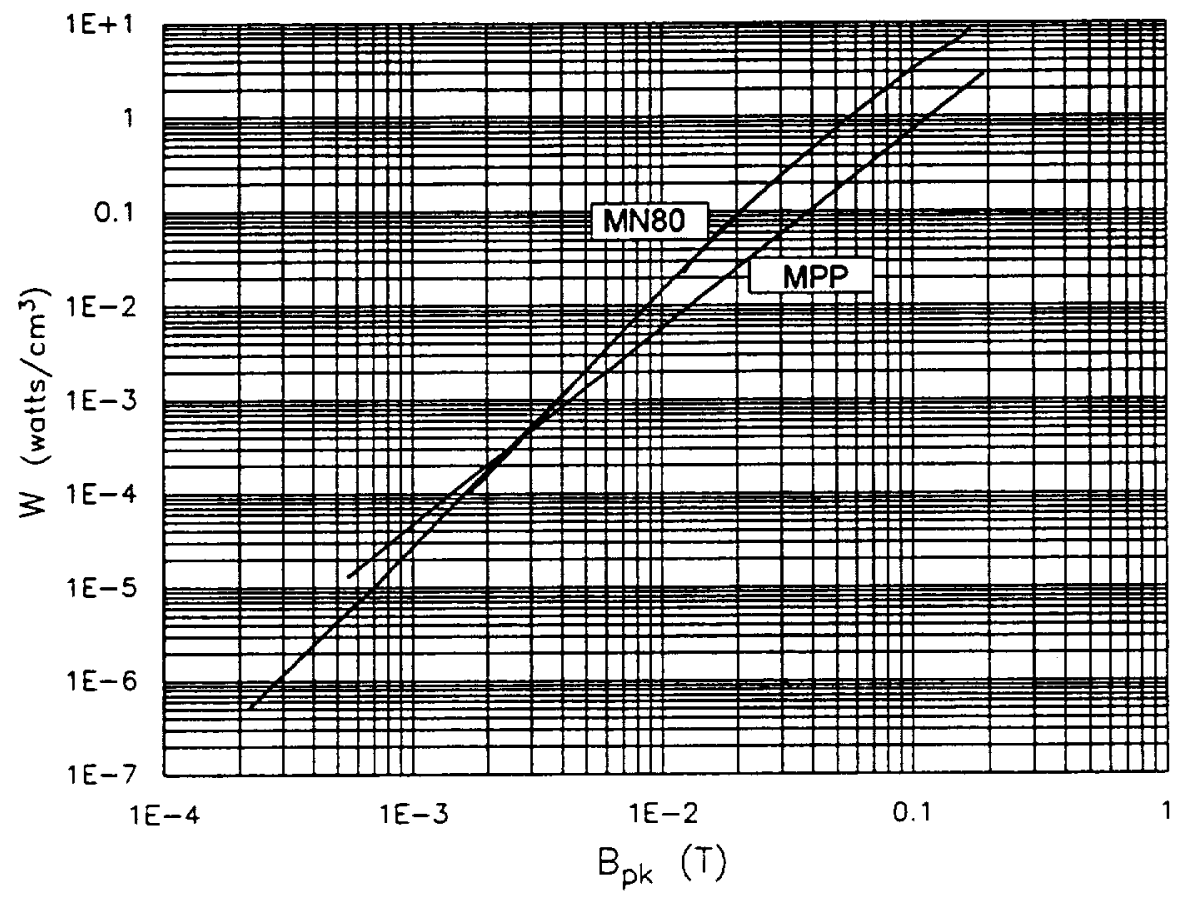

Figure 6. Comparative specific core loss for the MPP and MN80 ferrite powder, using Eq. 22. Frequency varies from 60 to $62 \mathrm{kHz}$ over the MPP curve and from 51 to $58 \mathrm{kHz}$ over the MN80 curve due to variation of inductance with voltage. 


\begin{tabular}{|c|c|c|}
\hline \multicolumn{2}{|c|}{ REPORT DOCUMENTATION PAGE } & $\begin{array}{l}\text { Form Approved } \\
\text { OMB No. } 0704-0188\end{array}$ \\
\hline \multicolumn{3}{|c|}{ 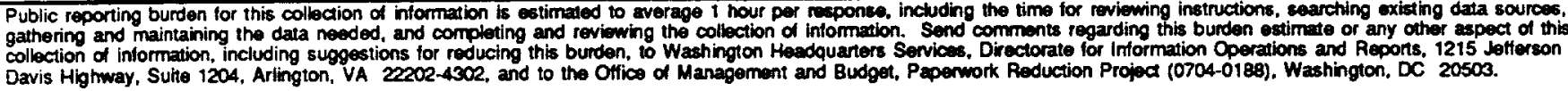 } \\
\hline 1. AGENCY USE ONLY (Leave blank) & $\begin{array}{l}\text { 2. REPOFT DATE } \\
\text { August } 1995\end{array}$ & $\begin{array}{l}\text { 3. REPORT TYPE AND DATES COVEAED } \\
\text { Final Contractor Report }\end{array}$ \\
\hline \multicolumn{2}{|c|}{$\begin{array}{l}\text { 4. TITE AND SUBTTLE } \\
\text { Improved L-C Resonant Decay Technique for Q Measurement of Quasilinear } \\
\text { Power Inductors: New Results for MPP and Ferrite Powdered Cores }\end{array}$} & \multirow{2}{*}{$\begin{array}{l}\text { 5. FUNDING NUMBERS } \\
\text { WU-233-01-0C } \\
\text { C-NAS3-27186 }\end{array}$} \\
\hline \multicolumn{2}{|c|}{$\begin{array}{l}\text { 6. AUTHOF(S) } \\
\text { Janis M. Niedra and Scou S. Gerber }\end{array}$} & \\
\hline $\begin{array}{l}\text { 7. PERFORMING ORGANIZATION MM } \\
\text { NYMA Inc. } \\
\text { 2001 Aerospace Parkway } \\
\text { Brook Park, Ohio } 44142\end{array}$ & 5) AND ADDRESS(ES) & $\begin{array}{l}\text { 8. PERFORMING ORGANIZATION } \\
\text { REPORT NUMBER } \\
\text { E-9823 }\end{array}$ \\
\hline $\begin{array}{l}\text { 9. SPONSORINGIMONITORING AGEM } \\
\text { National Aeronautics and Sp } \\
\text { Lewis Research Center } \\
\text { Cleveland, Ohio } 44135-31\end{array}$ & $\begin{array}{l}\text { NAME(S) AND ADDRESS(ES) } \\
\text { Administration }\end{array}$ & $\begin{array}{l}\text { 10. SPONSORINGMNONITORING } \\
\text { AGENCY REPORT NUMBER } \\
\text { NASA CR-198373 }\end{array}$ \\
\hline
\end{tabular}

11. SUPPLEMENTARY NOTES

Project manager, Gene E. Schwarze, Power Technology Division, NASA Lewis Research Center, organization code 5430, (216) 433-6117.

12a. DISTRIBUTIONAVAILABILTY STATENENT

12b. DISTRIBUTION CODE

Unclassified - Unlimited

Subject Category 33

This publication is available from the NASA Center for Aerospace Information, (301) 621-0390.

13. ABSTRACT (Maximum 200 words)

The L-C resonant decay technique for measuring circuit $Q$ or losses is improved by eliminating the switch from the inductor-capacitor loop. A MOSFET switch is used instead to momentarily connect the resonant circuit to an exciting voltage source, which itself is gated off during the decay transient. Very reproducible, low duty cycle data could be taken this way over a dynamic voltage range of at least 10:1. Circuit $Q$ is computed from a polynomial fit to the sequence of the decaying voltage maxima. This method was applied to measure the losses at $60 \mathrm{kHz}$ in inductors having loose powder cores of moly permalloy and an $\mathrm{Mn}-\mathrm{Zn}$ power ferrite. After the copper and capacitor losses are separated out, the resulting specific core loss is shown to be roughly as expected for the MPP powder, but anomalously high for the ferrite powder. Possible causes are mentioned.

14. SUBJECT TERMS

Core loss; Inductor, Resonant decay; Magnetic measurements; Q measurement; 15. NUMBEA OF PAGES Magnetic material; Ferrite; Moly permalloy

16. PRICE CODE

$\mathrm{A} 03$

\begin{tabular}{|c|c|}
\hline 17. SECURTY CLASSIFICATION & 18. SECURTY CLASSIFICATION \\
OF REPORT & $\begin{array}{c}\text { OF THS PAGE } \\
\text { Unclassified }\end{array}$ \\
Unclassified
\end{tabular}

NSN 7540-01-280-5500
19. SECURTY CLASSIFICATION OF ABSTRACT Unclassified 